\title{
TOPOGRAPHIC CHARACTERISTICS IN THE ABLATION AREA OF THE KHUMBU GLACIER, NEPAL HIMALAYA
}

\author{
by \\ O. Watanabe \\ (National Institute for Polar Research, Itabashi, Tokyo 173, Japan) \\ and \\ S. Iwata \\ (Department of Geography, Tokyo Metropolitan University, Setagaya, Tokyo 158, Japan) \\ and \\ H. Fushimi
}

(Lake Biwa Research Institute, Otsu, Shiga 520, Japan)

\begin{abstract}
Topographic sketch mapping of the whole ablation area of the Khumbu Glacier, East Nepal Himalaya, is performed, using a simple, stereo-photogrammetric method. This map shows that the surface morphology can be classified into 11 morphologic characteristics. Depending on their distribution and combination, the ablation area can be divided into four morphologic areas. Detailed maps, on a scale of $1: 1000-2500$, of these four areas indicate that the distribution and combination of these 11 morphologic characteristics result from thickness of the debris cover, supraglacial streams and ponds, and glacier dynamics. The irregularity in the ablation area of the Khumbu Glacier can be considered to be a consequence of the mass balance between rate of ice charge from upstream and irregular distribution of ablation rate, depending on debris-cover characteristics in situ.
\end{abstract}

\section{INTRODUCTION}

One of the most conspicuous morphological features on the southern slope of the Himalayan Mountains is the abundance of debris-covered glaciers. Debris-covered areas on glaciers are common on valley type glaciers with large ice tongues, but on smaller valley glaciers and cirque glaciers, debris-covered areas are small or lacking. On the other hand, on the northern slope of the Himalayan Mountains, including the southern part of the Tibetan Plateau, most glaciers have ablation areas without supraglacial debris or with small debris-covered areas.

The Khumbu Glacier has a $10 \mathrm{~km}$-long, debris-covered area. The debris-covered area shows complex morphological features, considered to be a consequence of morphological processes in situ. In order to make clear the process of formation of surface features, a topographic survey and mapping of surface morphology were carried out on the Khumbu Glacier during the monsoon season (JuneSeptember) of 1978.

The Khumbu Glacier is situated in the Khumbu Himal region of east Nepal (Fig.1). The upper limit of the glacier is around $6800 \mathrm{~m}$ a.s.l., on the SW face of Mt. Sagarmatha (Qomolangma or Everest, $8848 \mathrm{~m}$ ) and $7500 \mathrm{~m}$ on the W. face of Lhotse $(8511 \mathrm{~m})$. The altitudes of the equilibrium line and the glacier terminus are about $5600 \mathrm{~m}$ and $4900 \mathrm{~m}$, respectively. The latest expansion of the glacier occurred between the 16th and 18th centuries (Fushimi, 1981). A comparison between present work and Müller's early work in 1956 (Müller, 1968) suggests that a change of

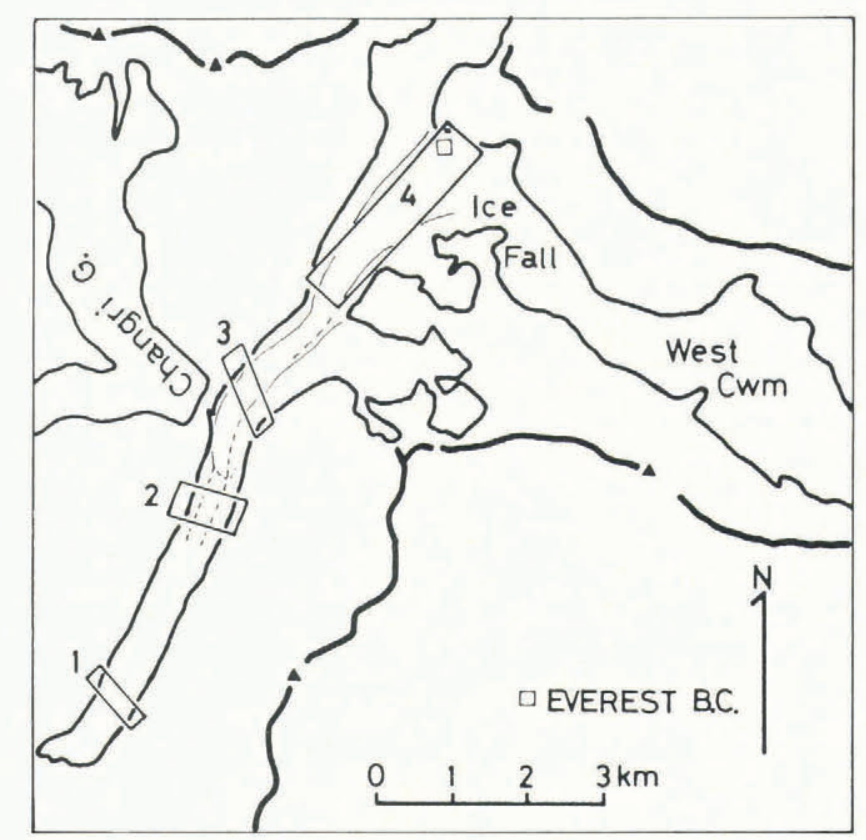

Fig.1. Study area on the Khumbu Glacier. Detailed research areas I-IV shown in frames $1-4 . \quad \mathrm{EL}=$ estimated equilibrium line.

surface condition of the ablation area may have occurred. Several large- and medium-scale topographic maps (e.g. R.G.S. map, Schneider map) are available in this region.

\section{TOPOGRAPHIC SURVEY}

The topographic sketch map shown in Fig.2A was completed by the following method. For the control of surveying, a traverse line and triangulation network were established, using a Wild T2 theodolite. Ground photographs in 400 stereo-pairs were taken from the lateral moraine ridge, using an ordinary $35 \mathrm{~mm}$ camera. These cover the whole ablation area and the positions of the key forms on the glacier were fixed graphically on the map. Though contour lines could not be drawn, details of the landforms were drawn from these ground photographs and from the 


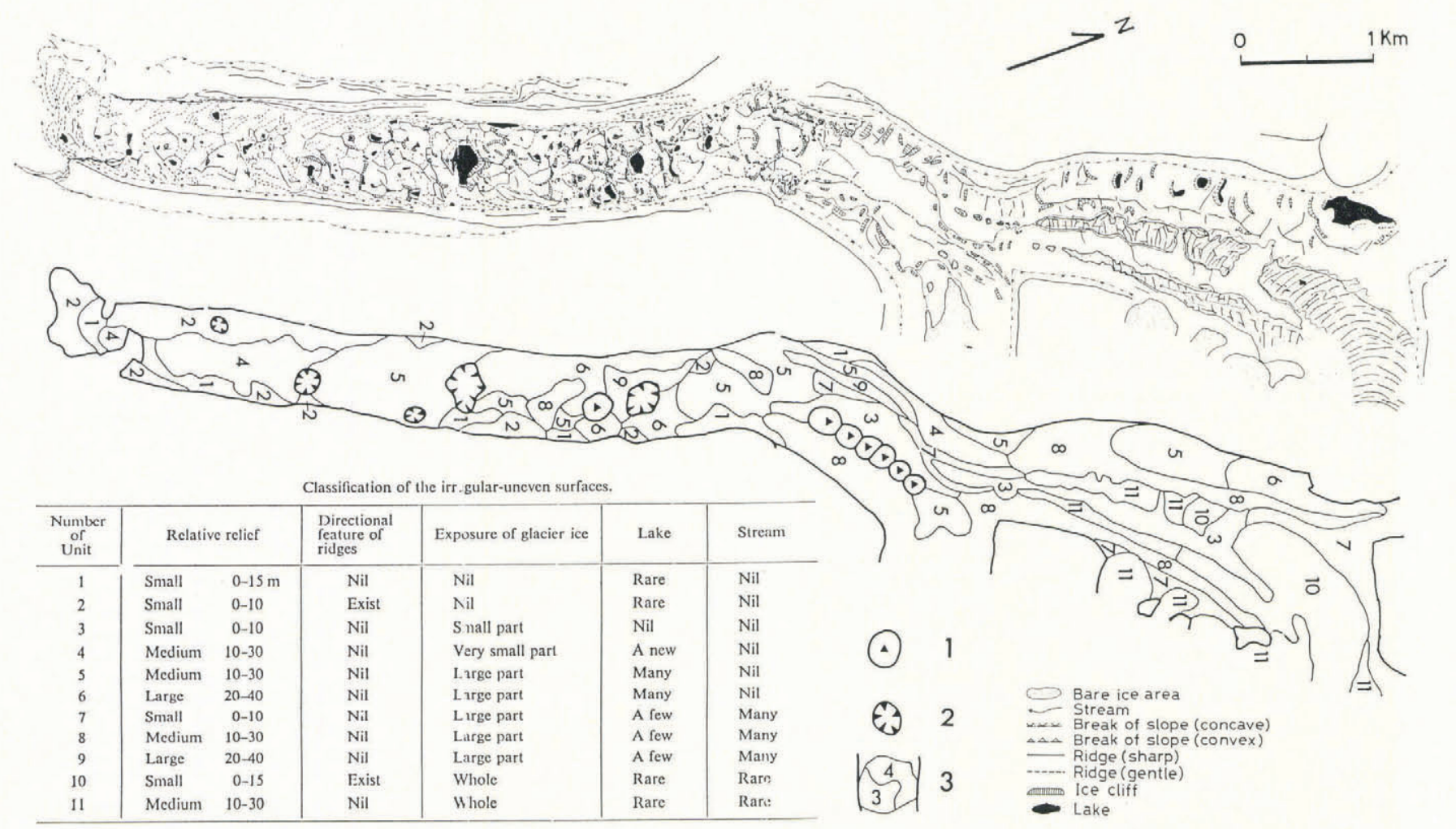

Fig.2. Topographic map of the whole ablation area. $\mathbf{A}=$ topographic sketch map, $\mathrm{B}=$ classification of the surface morphology. The numbers 1-3 represent large debris-covered cone, large hollow, and irregularly-uneven surface, respectively.

50 oblique aerial photographs, which include stereo-pairs and almost vertical aerial photographs, taken in October and December of 1978 .

In order to investigate the morphology on a small scale and the agents of morphologic processes, large-scale maps were made in four, detailed, research areas. In Areas I, II and III, contoured maps were made on a scale of 1:1000, by framework surveying with a theodolite and by plane-table topographical surveying with a telescopic alidade. Area IV was surveyed on a scale of $1: 2500$ by tacheometry (the use of stadia readings). The locations of these detailed research areas I-IV are shown in Fig.1.

\section{SURFACE MORPHOLOGY AND MORPHOGENETIC PROCESSES}

Details of surface morphology in the ablation area have already been reported by Iwata et. al. (1980). As the result of morphological mapping, the debris-covered surface is classified into 11 morphological units (Fig.2B). Glacial structures of the Khumbu Glacier have been reported (Fushimi, 1977), and distribution of supraglacial debris and ablation rate were also investigated during this research (Fushimi et. al., 1980; Inoue and Yoshida, 1980; Nakawo et. al., 1986). Surface morphogenetic processes were observed in four detailed research areas (Fig.3).

Figure 4 shows the schematic diagrams of the variations of several features and morphogenetic processes, along a longitudinal section of the glacier. Ablation at the glacier surface and ice discharge are shown by measured values; other quantities are shown as general tendencies.

In the highest part of the ablation area (Area IV), the ablation occurs by melting of bare ice and ice under the thin debris cover. These melting rates are almost constant over the whole area. It is suggested that the gentle undulations which characterize this area have developed by this spatial uniformity of the ablation rate. In Area III, 5-7 km from the terminus, dominant ablation around the supraglacial lakes and streams occurs, in addition to inactive ice melting under the debris cover. Here the glacier became stagnant, so the relief of the glacier surface becomes more pronounced. In the area, $3-5 \mathrm{~km}$ from the terminus, which includes Area II, the debris cover becomes thick enough to reduce ablation in the whole area to a small value. However, the amount of surface ablation on the ice cliffs and of the ablation around the supraglacial lakes

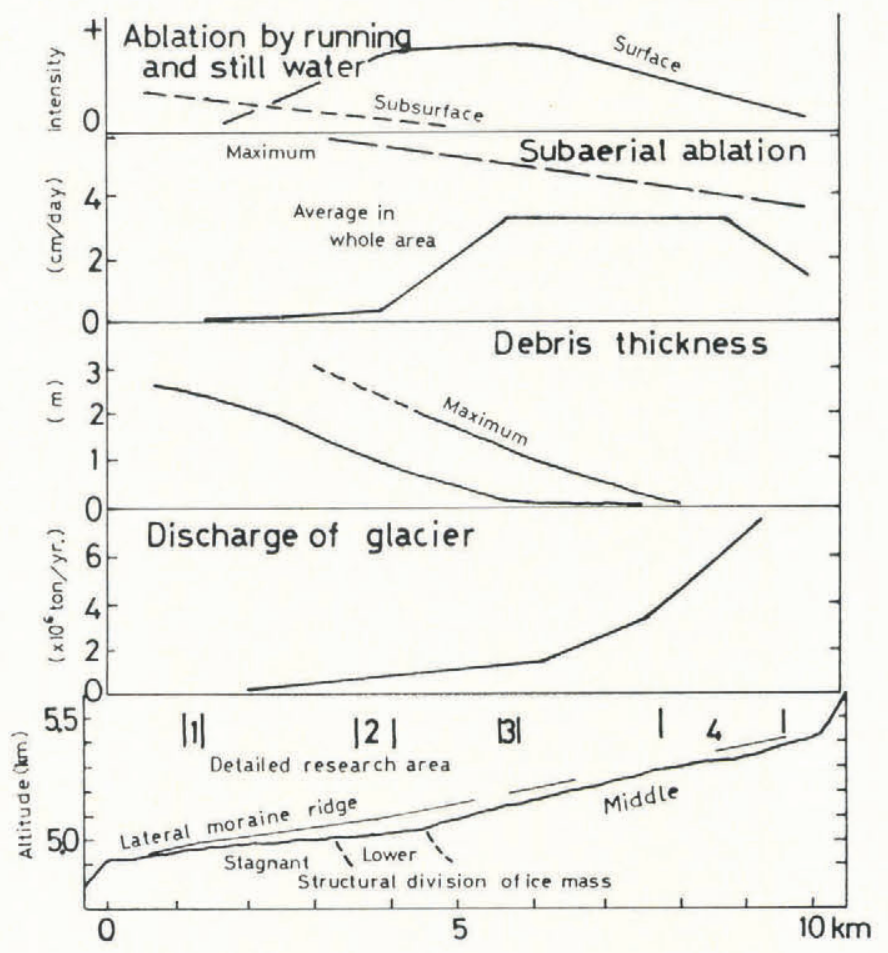

Fig.4. The schematic diagram of the morphogenetic process, along the longitudinal section of the glacier. Data of the ablation and discharge of glacier ice are from Inoue and Yoshida (1980) and Kodama and Mae (1976), respectively. 

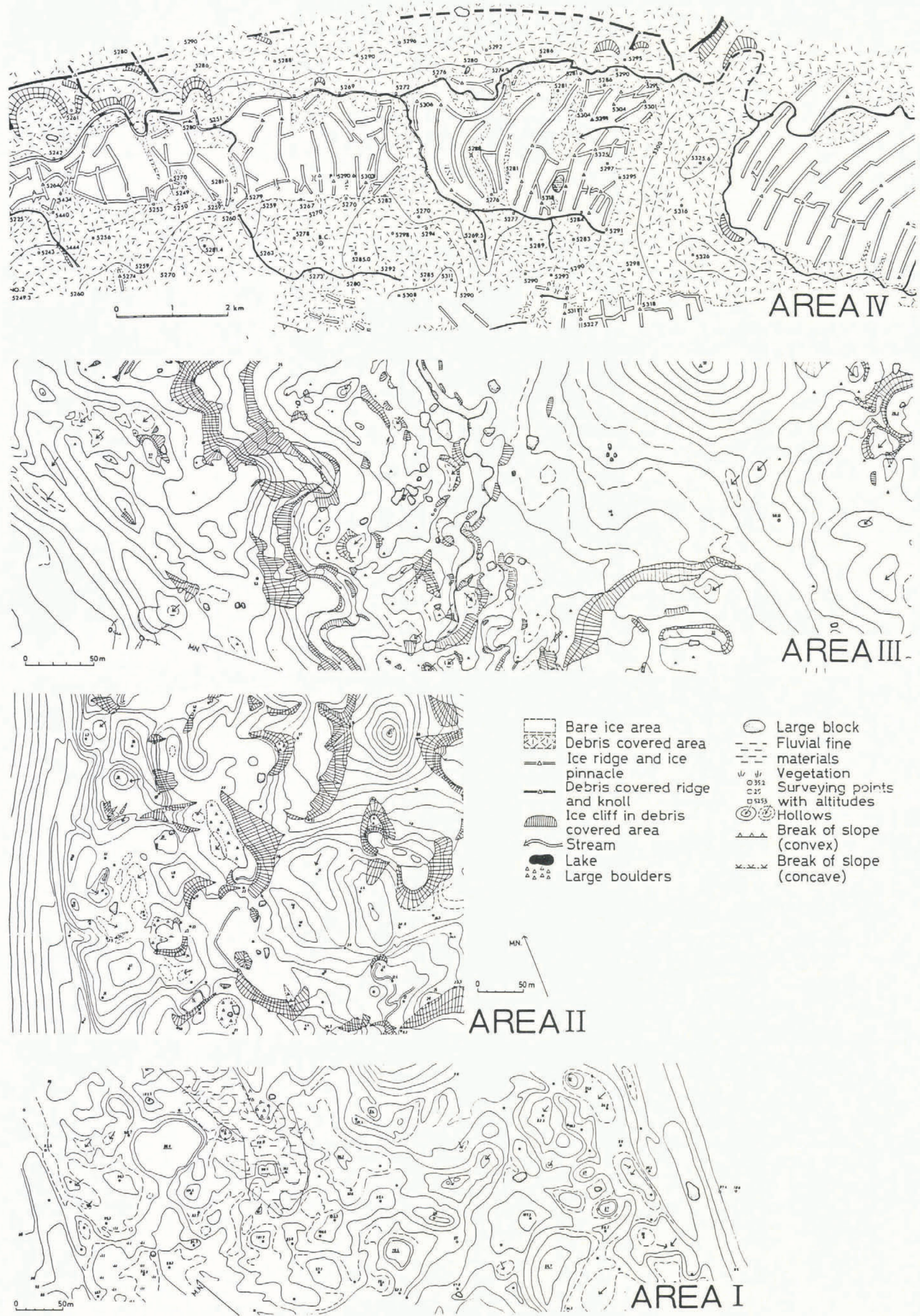

Fig.3. Topographic maps of the four, detailed research areas. 
and streams is still large. Therefore, the surface undulations become larger, as a consequence of the spatial differences of the ablation rate. The terminal area (last $2 \mathrm{~km}$ ) shows moderate relief and a stable condition of the surface debris. The thick debris cover protects the glacier ice from ablation, though slight melting can occur in subglacial or englacial channels. The glacier ice in this terminal zone is slowly diminishing in volume.

\section{REFERENCES}

Fushimi H 1977 Structural studies of glaciers in the Khumbu region. Seppyo. Journal of the Japanese Society of Snow and Ice, Special Issue 39: 30-39

Fushimi H 1981 Glacial history in the Khumbu region, Nepal Himalayas in relation to upheavals of the Great Himalayas. In Liu D-s (ed) Geological and ecological studies of Qinghai-Xizang Plateau. Beijing, Science Press: 1641-1648

Fushimi H, Yoshida M, Watanabe O, Upadhyay B P 1980 Distributions and grain sizes of supraglacial debris in the Khumbu glacier, Khumbu region, east Nepal. Seppyo. Journal of the Japanese Society of Snow and Ice. Special Issue 41: $18-25$

Inoue J, Yoshida M 1980 Ablation and heat exchange over the Khumbu glacier. Seppyo. Journal of the Japanese Society of Snow and Ice. Special Issue 41: 26-33

Iwata S, Watanabe O, Fushimi H 1980 Surface morphology in the ablation area of the Khumbu glacier. Seppyo. Journal of the Japanese Society of Snow and Ice, Special Issue 41: 9-17

Kodama H, Mae S 1976 The flow of glacier in the Khumbu region. Seppyo. Journal of the Japanese Society of Snow and Ice. Special Issue 38: 33-36

Müller F 1968 Mittelf ristige Schwankungen der Oberflächengeschwindigkeit des Khumbugletschers am Mount Everest. Schweizerische Bauzeitung 86(31): 569-573

Nakawo M, Iwata S, Watanabe O, Yoshida M 1986 Processes for distribution of supraglacial debris on the Khumbu glacier, Nepal Himalaya. Annals of Glaciology 8: 129-131 